\title{
Educating university allied health students about gender-based violence: Report of a pilot study
}

\author{
F. Doran \& P. Orrock
}

\begin{abstract}
Introduction: Sexual harassment, bullying and discrimination occur across a range of healthcare settings, with frequent complaints made to health professional registration boards of Australia. Health professional education provides an ideal opportunity to ensure students understand the nature of gender-based violence (GBV) and how to prevent and address such behaviour. However, there has been minimal health professional curricula that incorporates an integrated focus on gender. The aim of this study was to increase awareness and knowledge of pre-registration health students of the context of GBV and for participants to learn bystander approaches to effectively intervene to reduce violence.

Methods: A violence prevention workshop incorporating a bystander approach was developed as a key component of the curriculum for a single discipline cohort of health students. Participants completed a survey pre and post workshop, where they provided responses, on a 5-point Likert scale, to statements exploring attitudes, knowledge and behaviours in relation to behaviours that constitute GBV. Within-subject pre- and postintervention statistical analysis was completed.
\end{abstract}

Results: The results demonstrated several significant positive changes to knowledge and attitude of the participants in relation to GBV.

Conclusions: The findings of the project can inform the development of integrated gender-focused education as a core competency for preparing health professional students across a range of disciplines in clinical health and public health curricula.

School of Health and Human Sciences, Southern Cross University, New South Wales, Australia

\section{Correspondence}

Frances Doran

School of Health and Human Sciences

Southern Cross University

PO Box 157

Lismore, NSW 2480

Australia

Tel: +61266203888

Email: frances.doran@scu.edu.au 
Keywords: professional education; health professional curricula; gender-based violence; sexual harassment; students; survey

\section{Introduction}

Sexual harassment, sexism and gender discrimination are common in workplaces, including healthcare settings (VEOHRC, 2020). Sexual harassment is more likely to occur in settings where stereotyped constructions of masculinity, sexism and gender discrimination are excused or tolerated (Our Watch, 2020). Gender-based violence (GBV) is a major public health issue (WHO, 2013) that occurs on a continuum (McMahon \& Banyard, 2012), ranging from demeaning attitudes to women and sexist jokes (AHRC, 2020) to sexual harassment (Kabat-Farr \& Crumley, 2019), and at its most severe, crimes against women, such as rape, sexual assault and family and domestic violence (Flood, 2019; Our Watch, 2020). These are significant public health issues, with attention drawn recently to their prevalence and associated dire effects within workplace settings with the \#MeToo movement and calls to end sexist attitudes and behaviours that condone violence against women (Fileborn et al., 2019; Jagsi, 2018).

The national professional boards of registered health practitioners in Australia frequently receive complaints about health professionals' behaviour (AHPRA, 2019; Bismark et al., 2020). AHPRA received 92 notifications about "sexual misconduct" and 1,167 about "boundary violations" in the 2018/2019 financial year (AHPRA, 2019). Results of the first Medical Training Survey, of almost 10,000 doctors, found more than one in three trainees experienced or witnessed bullying, harassment or discrimination (Medical Board of Australia and AHPRA, 2020). The report noted that bullying, harassment and discrimination negatively impact patient safety, constructive learning and the culture of healthcare and highlighted the need to strengthen professional behaviour. Male health professionals are identified as the main perpetrators of GBV (Our Watch, 2020) and key to engage in primary prevention programs (Wells \& Fotheringham, 2021).

Each of the national boards of health practitioners in Australia requires all registered health student practitioners to adhere to a code of conduct on professional behaviour (AHPRA 2019). It is, therefore, essential that students, as potential leaders, understand professional boundaries; the prevalence of sexism, gender discrimination and harassment; how to avoid unprofessional behaviour in workplace settings; and how to take necessary action towards achieving gender equality (VEOHRC, 2020). Sexual harassment and GBV are not women's issues; they are societal issues (AHRC, 2020). Healthcare professionals have a key role in addressing these issues and influencing cultural change. Primary prevention education to address GBV within health professional curriculum is warranted.

Health professional curricula must encompass these higher-order, values-based content areas to ensure students have a good understanding of GBV and knowledge of how to 
stop disrespectful behaviour (Fenton \& Jones, 2017). To date, an integrated focus on gender has largely been overlooked or sparsely covered (Siller et al., 2018; WHO, 2007) in health professional education, with curricula often densely packed and dominated by clinical skills and task-based learning outcomes (Lovi et al., 2018). The challenge is to ensure this content is covered with appropriate pedagogies aimed at ethical and moral outcomes. The literature based on transformative learning focuses on this issue, and experiential learning and content delivery by workshop are both highly regarded methods to engage the student-participant in deeper learning (Glisczinski, 2007).

Primary prevention education is key to creating culturally safe workplaces and influencing individuals to address the "drivers" of GBV (Our Watch, 2020). Though relatively new in Australia, these programs have a long history in the USA (Katz, 2018), with workshops commonly utilised to incorporate bystander approaches. Bystander approaches seek to promote individual awareness of gender inequity and change the social norms, which condone and perpetuate violence against women (Katz, 2018). Bystander approaches focus on leadership and the development of skills and knowledge of bystanders to interrupt GBV. The approach encourages men to be agents of change, alongside women (Wells \& Fotheringham, 2021), to advance gender equity (AHRC, 2020). This approach suits the role of health professionals, many of whom have capabilities for practice that include patient advocacy, community leadership and acknowledgement of the right to be treated with respect (AHPRA, 2020).

\section{Innovation}

\section{Methods}

A pilot study primary-prevention educational workshop was undertaken that aimed to increase awareness and knowledge of the context of GBV and to teach participants about bystander intervention approaches to reduce violence. All students enrolled in a core unit of study in the Master of Osteopathic Medicine $(n=57)$ at Southern Cross University, a regional Australian university, in 2019 were eligible to participate.

Osteopathy was deemed an appropriate professional training program in which to deliver this content, as unlike many other health professions, it has an even gender mix (AHPRA, 2019) and, therefore, presented a valuable opportunity to engage men. In addition, osteopaths (combined with chiropractors) are reported to have relatively high rates of notifications regarding sexual harassment or assault (Bismark et al., 2020). Ethics approval was granted from Southern Cross University Human Research Ethics Committee (ECN-17-182).

A 3-hour workshop was designed and delivered by an expert in GBV in April 2019. The workshop content covered behaviours that constitute GBV, including harassment; attitudes, beliefs and behaviours that normalise GBV; stereotyped constructions of masculinity and femininity; and leadership and bystander strategies to interrupt violence 
and challenge sexist behaviour. The content was delivered through facilitated discussion, scenarios, whole-of-group interactive activities and audio-visual material. Students were able to leave the workshop at any time without any repercussions, and attendance at the workshop was not compulsory. Informed consent was gained.

As there were no appropriate or suitable validated instruments, a survey was developed through a review of key literature (Alegría-Flores et al., 2017; ANROWS, 2018; Hutchinson \& Doran, 2017; McMahon et al., 2017) exploring attitudes, knowledge and behaviours in relation to GBV. Participants completed the survey pre and post workshop, providing responses to statements (25 questions) according to a 5-point Likert scale (1 = strongly agree to 5 = strongly disagree). Students were instructed to create their own code using the last 2 digits of their year of birth and the first two letters of their mother's first name. There were three open-ended questions at the end of the post survey: What was the most valuable part of the workshop? What are your suggestions for improvement? Do you have any further comments?

\section{Data analysis}

Within-subject pre- and post-intervention statistical analysis was completed (IBM Corp. Released 2019. IBM SPSS Statistics for Windows, Version 26.0. Armonk, NY: IBM Corp). Differences across time were analysed using paired-samples $t$-tests and were considered significant when $p<0.05$. The mean results indicate strength of agreement, with a score $<3$ indicating agreement and $>3$ indicating disagreement. Cross tabulations were performed for both age and gender effect on survey responses. The open-ended responses were collated.

\section{Evaluation}

\section{Results}

Forty participants attended the workshop. There were 21 matched pre and post surveys. The matched respondents were $52.4 \%$ female, and the median age category was $25-30$ years $(38.1 \%)$, with another $38 \%$ aged $31-50$ years. The group were all English speakers at home, and one student identified as Indigenous Australian. The pre- and postworkshop survey results, with significant results shaded, are presented in the appendix.

Key significant findings from the post-workshop survey were that after the violence prevention training, participants had significantly more agreement with the statements:

- Men's violence against women is common in our community; $t(20)=4.18, p<0.001$

- The majority of perpetrators of domestic violence are men; $t(19)=3.58, p<0.002$

- I have a good understanding of the non-physical types of men's violence against women; $t(20)=4.17, p<0.001$

- I am confident to explain the types of men's non-physical violence against women; $t(20)=5.56, p<0.001$ 
Also, after the violence prevention training, participants had significantly more disagreement with the statement:

If a woman dresses in a sexy manner (wearing short skirts or tight clothes for example), she is asking for sexual attention; $t(19)=3.33, p<0.004$

There were no significant differences for age or gender.

Fourteen students provided written comments about the workshop. Students commented positively on content, resources, the facilitation process and the way the information could be applied, as highlighted in comments below.

Gender stereotype explanations and examples; learning all the different variation $[s]$ of violence. (Participant 5)

Different ways I can act as a bystander. (Participant 1)

Very important conversation for all age groups and walks of life. (Participant 8)

The benefit of peer engagement was reflected in several comments.

Seeing the people I spend so much time with engage in such an important topic, especially the men in the room. (Participant 14)

Hearing peers' different opinions and views. (Participant 7)

Suggested ways to improve the workshop included a role-play activity to explore the content more deeply, a broader spectrum of violence examples and compulsory attendance.

\section{Outcomes}

The results of this pilot educational workshop demonstrated several significant positive changes in this cohort. The students improved their knowledge of how common GBV is in the community and the gendered nature of violence, and their understanding that most perpetrators of violence are men. Post workshop there was a significant shift in gender respectful attitudes in relation to not blaming women's choice of clothing for perpetrators' behaviour. This is important given attitudes that excuse, blame, condone and minimise violence can contribute to a culture of support for violence (Our Watch, 2020). Whilst most Australians do not accept sexism and want to address it, nearly one quarter of Australians see no harm in telling sexist jokes (Webster et al., 2018). This is comparable to international estimates, where $28 \%$ of men around the world think it is acceptable to tell sexist jokes or stories at work (Global Institute for Women's Leadership, 2020). Participants in this study significantly improved their understanding of what constitutes sexist behaviour, and there was a non-significant trend towards speaking out and taking action against sexist language. Violence prevention education needs to dispel myths to reduce the prevalence of sexual harassment in healthcare contexts where gender stereotypes remain unchallenged and sexism is excused or tolerated (AHRC, 2020). The 
results from this pilot intervention are encouraging and offer a way to dispel myths and promote understanding of the drivers of GBV, which include gender stereotypes and sexism (Our Watch, 2020).

A clear understanding of the context and spectrum of violence is an important influence on attitude and willingness to intervene to address the issue (Katz, 2018). Whilst this project did not directly assess behaviour, the findings demonstrate a positive trend for all participants to step up as bystanders and a willingness to intervene to address sexism and disrespectful attitudes.

Students in this study indicated support for gender-based education within their undergraduate curriculum. An integrated curriculum to address GBV (Yang, 2020) would assist healthcare students to meet professional requirements and equip them to become effective global citizens and agents of "social good" (VEOHR, 2020). Knowledge about the implications of behaviours that are unacceptable are a precursor to action. Whilst the benefit of the bystander approach is that all participants are engaged as proactive bystanders to address GBV (Katz, 2018), it is particularly important to engage men as bystanders as they often hold positions of power, can influence culture and can advocate for change (Our Watch, 2020). A global study of almost 300 men engaged in antiviolence work found that bystander willingness was supported with self-efficacy to engage in bystander behaviour, positive beliefs about the contributions of antiviolence involvement and an awareness of male privilege (Casey et al., 2019).

Post-workshop comments reflected the value of the workshop for future health professionals, with suggestions for more specific skills to address potential issues in clinical practice. Education for undergraduate healthcare students about GBV can provide practical tips for how to speak up against sexism, gender discrimination and gender inequality to positively influence the culture of healthcare (Hennelly et al., 2019) and challenge attitudes, norms and behaviours that drive GBV (Our Watch, 2020). This is crucial to address what has been described as "endemic unprofessional behaviour in health care" (Westbrook et al., 2018, p. 380), with the true prevalence of discriminatory behaviours such as gender harassment, offensive remarks and practices most likely under-reported. Our pilot study suggests the benefits of a workshop format to stimulate discussion about GBV with peers in a safe context.

As a pilot study, the outcomes of this brief educational intervention of a facilitated workshop are promising as a way to inform the development of GBV education within undergraduate health student curricula. A larger study based on this pilot could help build an Australian evidence base for effective gender-based education (Siller et al., 2018) to address the prevalence of sexual harassment within healthcare and prepare health practitioners to meet professional standards of practice. As osteopaths and other disciplines are registered health practitioners expected to abide by ethical principles and capabilities that include patient advocacy and community leadership, it is essential 
they recognise GBV and act to support clients in both the clinical and community environment. The use of experiential and workshop-based pedagogies appears promising to engage students at this level of knowledge and understanding.

\section{Limitations}

There were a number of limitations to the data, including the small sample size from one discipline and the limitations of a pre-post design. A simpler coding system may have improved the rate of post-workshop matching. Not all students attended the noncompulsory workshop, and a few students left the workshop early without expressing their reasons.

\section{What next?}

Workshops in GBV delivered to pre-registration healthcare students can potentially enhance knowledge and skills that are aligned with necessary graduate and professional attributes in practice and in the community. There were areas where knowledge and attitudinal changes from the workshop were not significant, and these could be emphasised more in future workshops, for example, focusing on the types and impacts of non-physical violence and providing training in different ways people can take action to prevent or stop abusive behaviour towards women. Larger interventions could possibly show significant age and gender differences. A series of integrated workshops throughout the curriculum with a focus on behavioural change may improve the results. However, this brief educational workshop intervention has demonstrated promising results from an innovative pedagogy that can be integrated into core curriculum across a range of health disciplines.

\section{Acknowledgements}

Thank you to our GBV expert for developing and delivering the workshops.

\section{Conflicts of interest and funding}

This research was supported by an ANZHAPE Research Grant in 2019. The authors report no conflicts of interest.

\section{References}

Alegría-Flores, K., Raker, K., Pleasants, R. K., Weaver, M. A., \& Weinberger, M. (2017). Preventing interpersonal violence on college campuses. Journal of Interpersonal Violence, 32(7), 1103-1126. https://doi.org/10.1177/0886260515587666

Australian's National Research Organisation for Women's Safety (ANROWS). (2018). National Community Attitudes Towards Violence Against Women Survey (NCAS). https://www.anrows.org.au/research-program/ncas/ 
Australian Health Practitioners Regulation Agency (AHRPA). (2019). National boards. https://www.ahpra.gov.au/National-Boards.aspx

Australian Human Rights Commission (AHRC). (2020). Respect@work: Sexual harassment national inquiry report. https://humanrights.gov.au/our-work/sexdiscrimination/publications/respectwork-sexual-harassment-national-inquiryreport-2020

Bismark, M. M., Studdert, D. M., Morton, K., Paterson, R., Spittal, M. J., \& Taouk, Y. (2020). Sexual misconduct by health professionals in Australia, 2011-2016: A retrospective analysis of notifications to health regulators. Medical Journal of Australia, 213(5), 218-224. https://doi.org/10.5694/mja2.50706

Casey, E. A., Allen, C. T., Tolman, R. M., Carlson, J. M., \& Leek, C. (2019). Walking the walk or just talk? A global examination of men's intentions to take violence preventative action. Journal of Aggression, Maltreatment \& Trauma, 28(9), 10381056. https://doi.org/10.1080/10926771.2018.1446480

Fenton, R., \& Jones, C. (2017). An exploratory study on the beliefs about gender-based violence held by incoming undergraduates in England. Journal of Gender-Based Violence, 1(2), 147-167. https://doi.org/10.1332/239868017X15090095609822

Fileborn, B., Loney-Howes, R., \& Hindes, S. (2019, March 8). \#MeToo has changed the media landscape, but in Australia there is still much to be done. The Conversation. http:/theconversation.com/metoo-has-changed-the-media-landscape-but-in-australiathere-is-still-much-to-be-done-111612

Flood, M. (2019). Engaging men and boys in violence prevention. Palgrave Macmillan. https://doi.org/10.1057/978-1-137-44208-6 2

Glisczinski, D. (2007). Transformative higher education: A meaningful degree of understanding. Journal of Transformative Education, 5(4), 317-328. https://doi. org/10.1177/1541344607312838

Global Institute for Women's Leadership. (2020). International Women's Day. https:// www.kcl.ac.uk/giwl/assets/international-womens-day-2020.pdf

Hennelly, S., Hussain, S., Hale, T., Cadle, M., Brooke, J., \& Davies, E. ( 2019). University student attitudes to prosocial bystander behaviours. Health Education, 119(5/6), 408-424. https://doi.org/10.1108/HE-05-2019-0023 
Hutchinson, M., \& Doran, F. (2017). Psychometric testing of inventory of beliefs and attitudes on domestic violence. Nurse Researcher, 25(1), 30-36. https://doi. org/10.7748/nr.2017.e1469

Jagsi, R. (2018). Sexual harassment in medicine: \#MeToo. New England Journal of Medicine, 378(3), 209-211. https://doi.org/10.1056/NEJMp1715962

Kabat-Farr, D., \& Crumley, E. (2019). Sexual harassment in healthcare: A psychological perspective. The Online Journal of Issues in Nursing, 24(1), Manuscript 4. https://doi. org/10.3912/OJIN.Vol24No01Man04

Katz, J. (2018). Bystander training as leadership training: Notes on the origins, philosophy, and pedagogy of the mentors in violence prevention model. Violence Against Women, 24(15), 1755-1776. https://doi.org/10.1177/1077801217753322

Lovi, R., Hurley, J., \& Hutchinson, M. (2018). Qualitative findings from an Australian study of inter-partner violence content within undergraduate health curriculum. Nurse Education Today, 70, 1-7. https:/doi.org/10.1016/j.nedt.2018.07.012

Medical Board of Australia and AHPRA. (2020). Medical training survey. https://www. medicaltrainingsurvey.gov.au/Results/Reports-and-results

McMahon, S., \& Banyard, V. L. (2012). When can I help? A conceptual framework for the prevention of sexual violence through bystander intervention. Trauma Violence Abuse, 13(1), 3-14. https://doi.org/10.1177/1524838011426015

McMahon, S., Palmer, J., \& Banyard, V. (2017). Measuring bystander behaviour in the context of sexual violence prevention: Lessons learned and new directions. Journal of Interpersonal Violence, 32(16), 2396-2418. https://doi.org/10.1177/0886260515591979

Our Watch. (2020). National primary prevention report. https://media-cdn.ourwatch.org. au/wp-content/uploads/sites/2/2021/01/29140249/Our-Watch-National-primaryprevention-report-AA.pdf

Siller, H., Komlenac, N., Fink, H., Perkhofer, S., \& Hochleitner, M. (2018). Promoting gender in medical and allied health professions education: Influence on students' gender awareness. Health Care for Women International, 39(9), 1056-1072. https:// doi.org/10.1080/07399332.2017.1395881 
Victorian Equal Opportunity and Human Rights Commission. (2020). Guideline: Preventing and responding to workplace sexual harassmen - Complying with the Equal Opportunity Act 2010. https://www.humanrights.vic.gov.au/resources/sexualharassment-guideline/

Webster, K., Diemer, K., Honey, N., Mannix, S., Mickle, J., \& Ward, A. (2018). Australians' attitudes to violence against women and gender equality: Findings from the 2017 National Community Attitudes Towards Violence Against Women Survey (NCAS) research report. https://ncas.anrows.org.au/wp-content/uploads/2019/03/NCASreport-2018.pdf

Wells, L., \& Fotheringham, S. (2021). A global review of violence prevention plans: Where are the men and boys? International Social Work. https://doi. org/10.1177/0020872820963430

Westbrook, J., Sunderland, N., Atkinson, V., Jones, C., \& Braithwaite, J. (2018). Endemic unprofessional behaviour in health care: The mandate for a change in approach. Medical Journal of Australia, 209(9), 380-381. https://doi.org/10.5694/mja17.01261

World Health Organisation (WHO). (2007). Integrating gender into the curricula for health professionals: Meeting report. https://www.who.int/gender/documents/GWH curricula_web2.pdf

Yang, H.-C. (2020). What should be taught and what is taught: Integrating gender into medical and health professions education for medical and nursing students. International Journal of Environmental Research and Public Health, 17(18), 6555. https://doi.org/10.3390/ijerph17186555 
Survey Results

\begin{tabular}{|c|c|c|c|c|c|c|c|c|c|}
\hline Statement & $\begin{array}{c}\text { Pre } \\
\mathbf{M}(\mathbf{S D})^{*}\end{array}$ & $95 \% \mathrm{CI}$ & $\begin{array}{l}\text { Post } \\
\text { M (SD)* }\end{array}$ & $95 \% \mathrm{Cl}$ & M diff & SD & $t$ & $d f$ & $p$ \\
\hline Sexual harassment is common & $1.95(0.97)$ & -0.29 & $1.74(1.10)$ & 0.71 & 0.21 & 1.03 & 0.89 & 18 & 0.385 \\
\hline $\begin{array}{l}\text { Women often make false reports of } \\
\text { sexual assault }\end{array}$ & $3.52(0.81)$ & -0.41 & $3.52(0.93)$ & 0.41 & 0 & .89 & 0 & 20 & 1 \\
\hline $\begin{array}{l}\text { Sexual assault and sexual } \\
\text { harassment are not a big deal }\end{array}$ & $4.90(0.44)$ & -0.14 & $4.90(0.30)$ & 0.14 & 0 & .32 & 0 & 20 & 1 \\
\hline $\begin{array}{l}\text { Men's violence against women is } \\
\text { common in our community }\end{array}$ & $2.29(0.64)$ & 0.36 & $1.57(0.75)$ & 1.07 & 0.71 & 0.78 & 4.18 & 20 & $<0.001$ \\
\hline $\begin{array}{l}\text { Attitudes about gender roles and } \\
\text { relationships are contributing factors } \\
\text { in men's violence against women }\end{array}$ & $2.14(0.48)$ & -1.00 & $1.86(0.79)$ & 0.67 & 0.29 & 0.85 & 1.55 & 20 & 0.137 \\
\hline $\begin{array}{l}\text { The majority of perpetrators of } \\
\text { domestic violence are men }\end{array}$ & $2.75(0.85)$ & 0.27 & $2.10(0.79)$ & 1.03 & 0.65 & 0.81 & 3.58 & 19 & 0.002 \\
\hline $\begin{array}{l}\text { If a woman dresses in a sexy manner } \\
\text { (wearing short skirts or tight clothes, } \\
\text { for example), she is asking for sexual } \\
\text { attention }\end{array}$ & $4.05(0.83)$ & -0.73 & $4.50(0.61)$ & -0.17 & -0.45 & 0.61 & 3.33 & 19 & 0.004 \\
\hline $\begin{array}{l}\text { When guys make suggestive } \\
\text { comments about a woman's body, she } \\
\text { should take it as a compliment }\end{array}$ & $4.20(0.62)$ & 0.09 & $4.40(0.75)$ & -1.45 & -0.20 & 0.62 & -1.45 & 19 & .163 \\
\hline $\begin{array}{l}\text { It's OK to call someone "slut", "bitch", } \\
\text { and "ho" to refer to women as long as } \\
\text { you are joking }\end{array}$ & $4.76(0.54)$ & -0.13 & $4.71(0.64)$ & 0.22 & 0.05 & 0.38 & 0.57 & 20 & .576 \\
\hline
\end{tabular}




\begin{tabular}{|c|c|c|c|c|c|c|c|c|c|}
\hline Statement & $\begin{array}{c}\text { Pre } \\
M(S D)^{*}\end{array}$ & $95 \% \mathrm{Cl}$ & $\begin{array}{c}\text { Post } \\
M(S D)^{*}\end{array}$ & $95 \% \mathrm{Cl}$ & $M$ diff & SD & $t$ & $d f$ & $p$ \\
\hline $\begin{array}{l}\text { Rape results from men not being able } \\
\text { to control their need for sex }\end{array}$ & $3.76(1.09)$ & -0.16 & $3.62(1.32)$ & 0.44 & 0.14 & 0.66 & 1.00 & 20 & .329 \\
\hline $\begin{array}{l}\text { If a woman is raped while she is } \\
\text { drunk or affected by drugs, then she } \\
\text { is at least partly responsible }\end{array}$ & $4.81(0.40)$ & 0.15 & $4.71(0.46)$ & 0.34 & 0.10 & 0.54 & 0.81 & 20 & .428 \\
\hline $\begin{array}{l}\text { A person is not really abusive } \\
\text { as long as they don't physically } \\
\text { harm someone }\end{array}$ & $4.86(0.36)$ & -0.15 & $4.90(0.30)$ & 0.05 & -0.05 & 0.22 & -1.00 & 20 & .329 \\
\hline $\begin{array}{l}\text { Intimate relationships between a man } \\
\text { and a woman work best when the } \\
\text { man is the leader }\end{array}$ & $4.52(0.68)$ & -0.06 & $4.19(1.12)$ & 0.72 & 0.33 & 0.86 & 1.78 & 20 & .090 \\
\hline $\begin{array}{l}\text { In some circumstances, violence } \\
\text { against women is justified }\end{array}$ & $4.57(0.98)$ & -0.26 & $4.38(0.97)$ & 0.64 & 0.19 & 0.98 & 0.89 & 20 & .384 \\
\hline $\begin{array}{l}\text { What happens between two people, } \\
\text { including a man and a woman } \\
\text { physically fighting, is none of } \\
\text { my business }\end{array}$ & $4.24(0.83)$ & -0.28 & $4.05(0.92)$ & 0.66 & 0.19 & 1.03 & 0.85 & 20 & .407 \\
\hline $\begin{array}{l}\text { There are a number of different ways } \\
\text { people can take action to prevent } \\
\text { or stop abusive behaviour towards } \\
\text { a woman }\end{array}$ & $1.75(1.02)$ & -0.46 & $1.70(0.80)$ & 0.56 & 0.05 & 1.10 & 0.20 & 19 & .841 \\
\hline $\begin{array}{l}\text { If I saw a man behaving abusively to } \\
\text { a woman, I would likely speak out or } \\
\text { take action }\end{array}$ & $2.05(0.69)$ & -0.20 & $1.90(0.45)$ & 0.50 & 0.15 & 0.75 & 0.90 & 19 & .379 \\
\hline $\begin{array}{l}\text { If I saw a man using sexist language } \\
\text { or calling women derogatory names, I } \\
\text { would likely speak out or take action }\end{array}$ & $2.20(0.52)$ & -0.04 & $1.90(0.55)$ & 0.64 & 0.30 & 0.73 & 1.83 & 19 & .083 \\
\hline
\end{tabular}




\begin{tabular}{|c|c|c|c|c|c|c|c|c|c|}
\hline Statement & $\begin{array}{c}\text { Pre } \\
M(S D) *\end{array}$ & $95 \% \mathrm{Cl}$ & $\begin{array}{c}\text { Post } \\
M(S D)^{*}\end{array}$ & $95 \% \mathrm{Cl}$ & M diff & SD & $t$ & $d f$ & $p$ \\
\hline $\begin{array}{l}\text { A bystander has the potential } \\
\text { to prevent sexual assault and } \\
\text { sexual harassment }\end{array}$ & $1.70(0.66)$ & -0.09 & $1.45(0.61)$ & 0.59 & 0.52 & 0.72 & 1.56 & 19 & .135 \\
\hline $\begin{array}{l}\text { I would be willing to speak out or } \\
\text { take action if I saw anyone behaving } \\
\text { abusively towards another }\end{array}$ & $2.11(0.57)$ & -0.05 & $1.89(0.57)$ & 0.47 & 0.21 & 0.54 & 1.71 & 18 & .104 \\
\hline $\begin{array}{l}\text { I would be willing to speak out or } \\
\text { take action if I saw a friend behaving } \\
\text { abusively towards another }\end{array}$ & $1.67(0.58)$ & -0.15 & $1.48(0.51)$ & 0.53 & 0.19 & 0.75 & 1.16 & 20 & .258 \\
\hline $\begin{array}{l}\text { I feel confident that I have the } \\
\text { skills to speak out or take action if } \\
\text { I saw anyone behaving abusively } \\
\text { towards another }\end{array}$ & $2.45(0.69)$ & -0.04 & $2.05(0.76)$ & 0.84 & 0.40 & 0.94 & 1.90 & 19 & .072 \\
\hline $\begin{array}{l}\text { I have a good understanding of the } \\
\text { non-physical types of men's violence } \\
\text { against women }\end{array}$ & $2.57(0.87)$ & 0.45 & $1.67(0.66)$ & 1.36 & 0.91 & 1.00 & 4.17 & 20 & $<.001$ \\
\hline $\begin{array}{l}\text { I am confident to explain the types } \\
\text { of men's non-physical violence } \\
\text { against women }\end{array}$ & $2.86(0.79)$ & 0.74 & $1.67(0.66)$ & 1.64 & 1.19 & 0.98 & 5.56 & 20 & $<.001$ \\
\hline $\begin{array}{l}\text { I believe men's violence against } \\
\text { women is preventable }\end{array}$ & $1.70(0.47)$ & -0.42 & $1.65(0.99)$ & 0.52 & 0.50 & 1.00 & 0.22 & 19 & .825 \\
\hline
\end{tabular}

